\title{
COVID-19: air pollution remains low as people stay at home
}

\author{
Sneha Gautam ${ }^{1}$
}

Received: 24 April 2020 / Accepted: 14 May 2020 / Published online: 21 May 2020

(C) Springer Nature B.V. 2020

\begin{abstract}
Coronavirus diseases 2019 (COVID-19) is transmitted worldwide in over a very short time, as it was originated in late 2019 from Wuhan city, China. To reduce the possible effects due to COVID-19, some sort of lockdown activities have been applied in many countries. In this regard, the outcomes reported bonus benefits to the natural environment showing a significant decrease in air pollution worldwide due to COVID-19. The National Aeronautics and Space Administration (NASA) and European Space Agency (ESA) released air pollution data for Asian and European countries to assess the significant changes in air quality. The main objective of the study is to compare the air quality data released by international agencies before and after the novel coronavirus pandemic.
\end{abstract}

Keywords Air pollutant $\cdot$ Coronavirus $\cdot$ COVID- $19 \cdot$ Nitrogen dioxide $\left(\mathrm{NO}_{2}\right) \cdot \mathrm{NASA} \cdot$ ESA

\section{Abbreviations}

COVID-19 Coronavirus diseases 2019

NASA National Aeronautics and Space Administration

ESA European Space Agency

$\mathrm{NO}_{2} \quad$ Nitrogen dioxide

TROPOMI Tropospheric Monitoring Instrument and

Ozone Monitoring Instrument

\section{Introduction}

The novel coronavirus started in Wuhan city, China, in late 2019 and it is now an ongoing global pandemic event (Gautam 2020; WHO 2020). Many researchers have reported that novel coronavirus is an acute respiratory disease, which may affect the lungs and respiratory system (Gautam and Trivedi 2020; Chen et al. 2020). As of April 24, 2020, there are a total of 2,709,483 and 190,861 persons reported as confirmed cases and as number of total deaths, respectively. There are three categories (i.e., history of smoking, older age, high blood pressure and heart diseases) which are considered important factors associated with the development of

Sneha Gautam

snehagautam@karunya.edu

1 Karunya Institute of Technology and Sciences, Coimbatore, Tamil Nadu 641114, India the diseases (Wu et al. 2020; Gautam and Trivedi 2020; Gautam and Hens 2020; Liu et al. 2020; Muhammad et al. 2020). According to a report released by the Italian Institute of Health, 481 patients having background diseases passed away due to novel coronavirus infection. In this regard, Fig. 1 shows the description of the background diseases evident in over $20 \%$ of the cases due to COVID-19.

The main sources of $\mathrm{NO}_{2}$ in the ambient atmosphere are transportation, power plants, and lighting (He et al. 2020; Sharma et al. 2020). Many studies (Saeha et al. 2020; Humbal et al. 2019; Arden Pope et al. 2004) have shown that the symptoms of harmful diseases (i.e., decreased lung function, premature death, lung disease, aggravated asthma, irregular heartbeat, and nonfatal heart attacks) reported due to long exposure to toxic component (i.e., nitrogen dioxide $\left(\mathrm{NO}_{2}\right)$ ). Persinger et al. (2002) reported the effects of long-term exposure to $\mathrm{NO}_{2}$ on lungs (damage to epithelial cells) and respiratory functions. Faustini et al. (2014) stated that the mortality rate can be increased due to the short- and long-term exposure to $\mathrm{NO}_{2}$. As per documents, a total of 2.6 million people are significantly affected due to the degradation of air quality. Cohen et al. (2017) reported respiratory and pathogenic effects due to exposure to air pollutants and also suggested a link between air pollution and sick building syndromes.

\section{Air quality during COVID-19}

Transportation activities have significantly been affected due to COVID-19 lockdowns, as there are less energy 


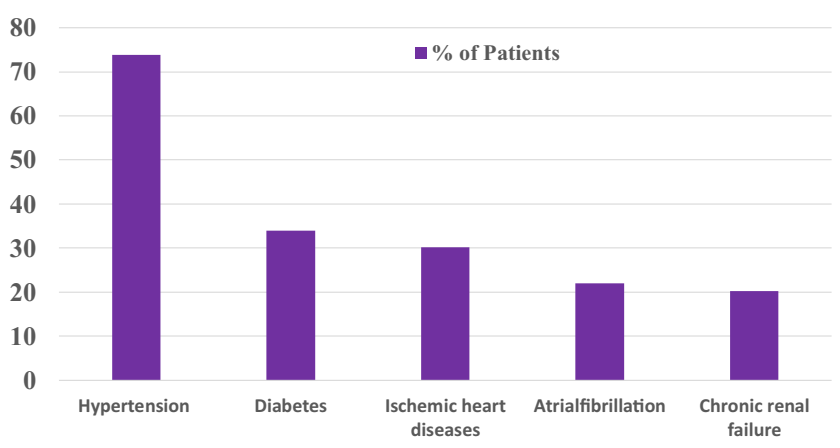

Fig. 1 Description of background diseases evident in over $20 \%$ of the cases (Ogen 2020)

consumption and less oil demand. The outcomes of the lockdown can be easily identified as an improvement of the environmental quality (i.e., air, water, noise). According to data recently released by the National Aeronautics and Space Administration (NASA) and European Space Agency (ESA), the environmental quality has improved and there was a 30\% reduction observed in the emission of $\mathrm{NO}_{2}$. The ESA and NASA collect the data (images) through Sentinel $-5 \mathrm{P}$ satellite and AURA satellite images which have produced using Tropospheric Monitoring Instrument and Ozone Monitoring Instrument (TROPOMI), respectively. Figure 2 shows the $\mathrm{NO}_{2}$ reduction (\%) in Asian and European countries due to COVID-19 lockdowns.

\section{South Asian countries}

A significant reduction in the percentage of $\mathrm{NO}_{2}$ in south Asian countries (i.e., China and India) can be seen (Figs. 3 and 4). The ESA collects air quality data by using TROPOMI instruments using Sentinel - 5P satellite during COVID-19 lockdowns. The results (i.e., $70 \%$ and $20-30 \% \mathrm{NO}_{2}$ reduction in India and China, respectively) indicate that there are significant changes in the level of $\mathrm{NO}_{2}$ identified in Asian countries due to COVID-19.

\section{European countries}

It can be seen that there is a variation in the concentration level of $\mathrm{NO}_{2}$ before and after COVID-19 (March 2019-March 2020) (Fig. 5). According to ESA (2020), the NO2 reduced $20-30 \%$ in European countries (i.e., Spain, Italy, and France) due to lockdown applied by respective governments. The possible images were collected by satellite (Sentinel - 5P) using the TROPOMI instrument.

According to the overall assessment of $\mathrm{NO}_{2}$ reduction during COVID-19 lockdowns, it can be observed that lockdown is more effective in Asian countries compared with that in European countries. Asian countries' fight against the COVID-19 outbreak has been unique. While Asian countries placed travel restrictions relatively early and many states quickly shut off access to public places, the country's high population density, overburdened public health infrastructure, high prevalence of non-communicable diseases, and the prospect of transmission from younger people to the elderly in joint families all stack the odds against effective containment. Moreover, the total number of confirmed cases and deaths is more in the European than in Asian countries. For further studies, the relationship between $\mathrm{NO}_{2}$ variation and the number of deaths due to novel coronavirus should be carried out.
Fig. $2 \mathrm{NO}_{2}$ emission reduction data during lockdown: Asian countries (a) and European countries (b) (source: NASA 2020 and ESA 2020)

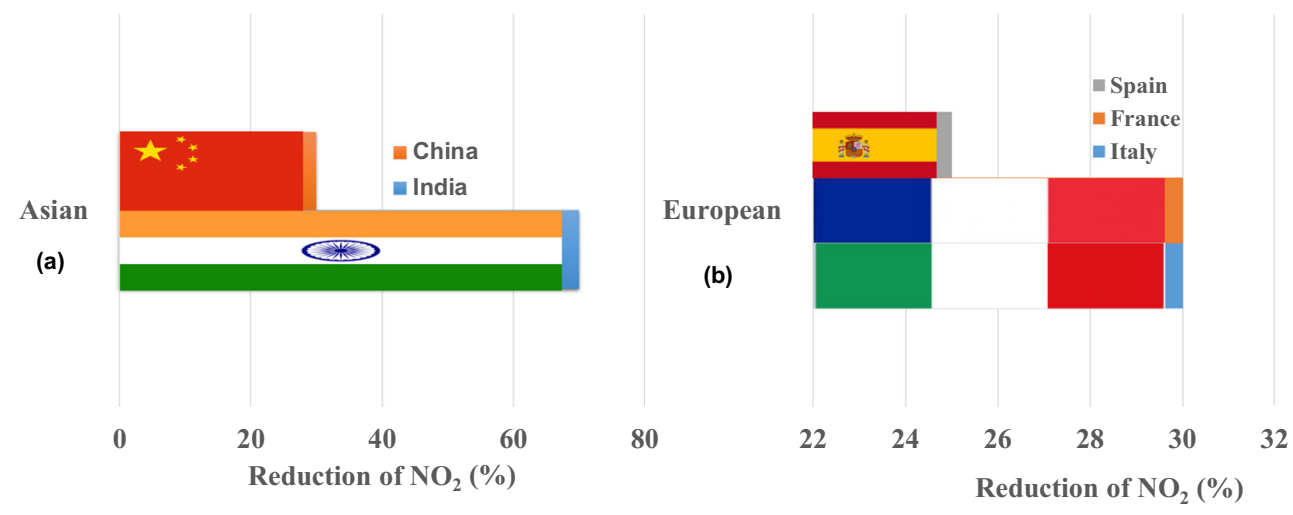




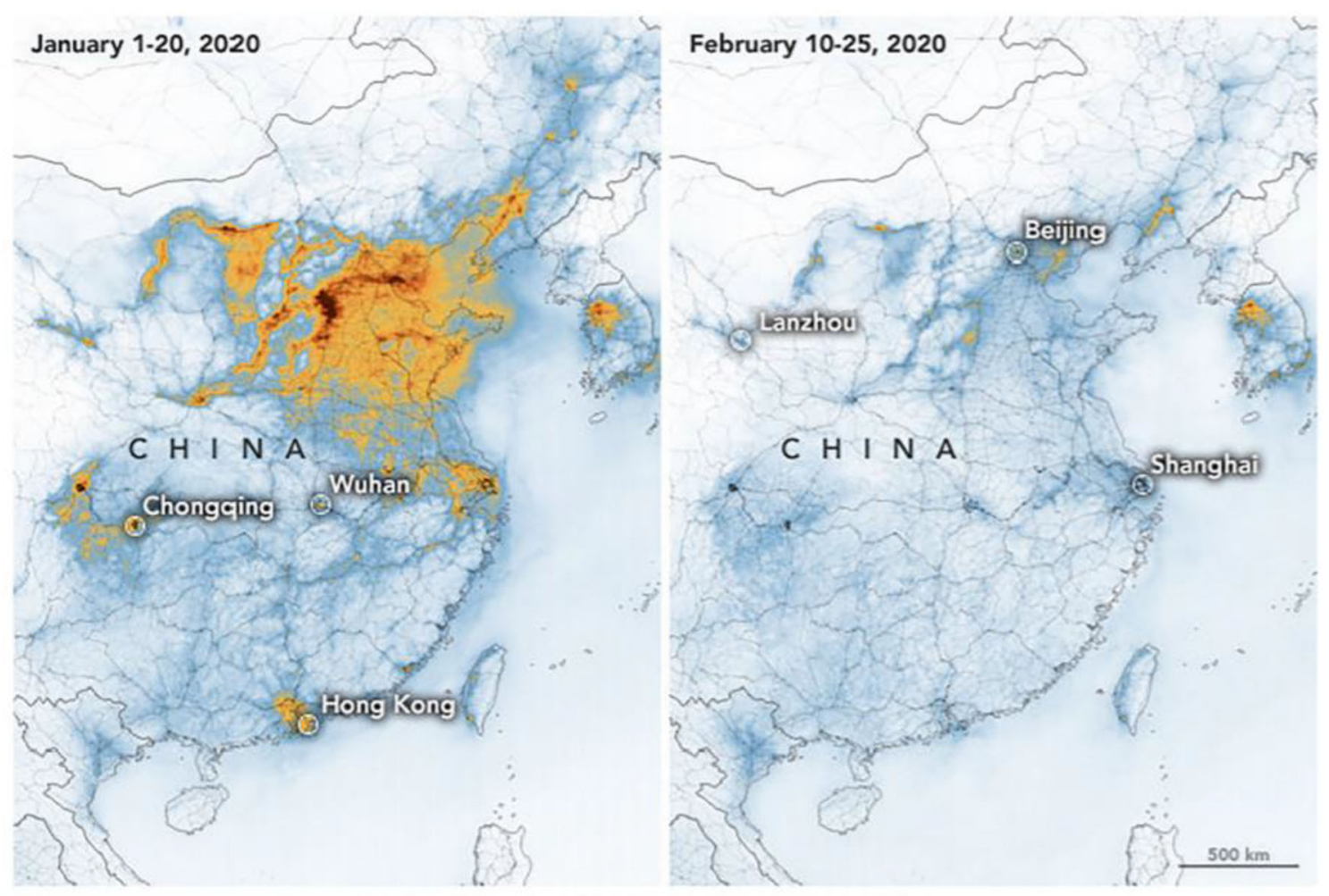

Mean Tropospheric $\mathrm{NO}_{2}$ Density $\left(\mu \mathrm{mol} / \mathrm{m}^{2}\right)$

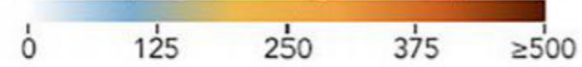

Fig. 3 Variation in the concentration of $\mathrm{NO}_{2}$ in China during the COVID-19 lockdowns (ESA 2020)
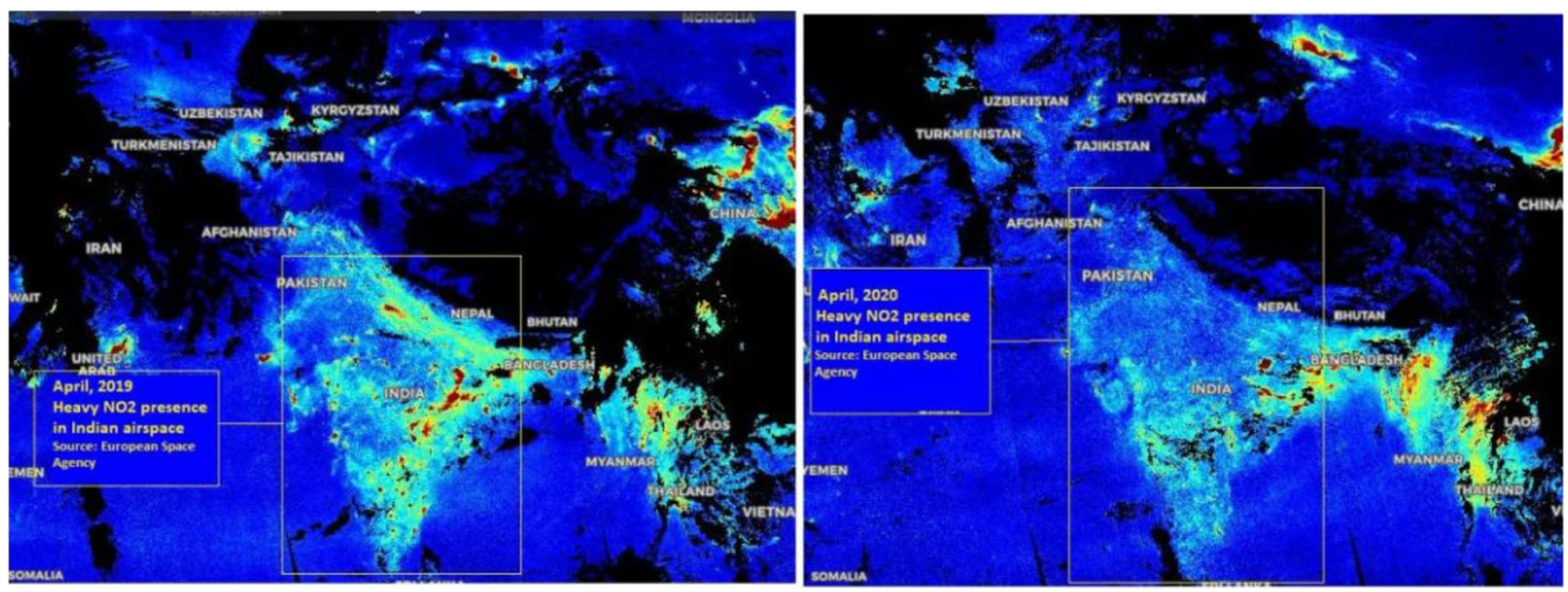

Fig. 4 Variation in the concentration of $\mathrm{NO}_{2}$ in India during COVID-19 lockdowns (ESA 2020) 

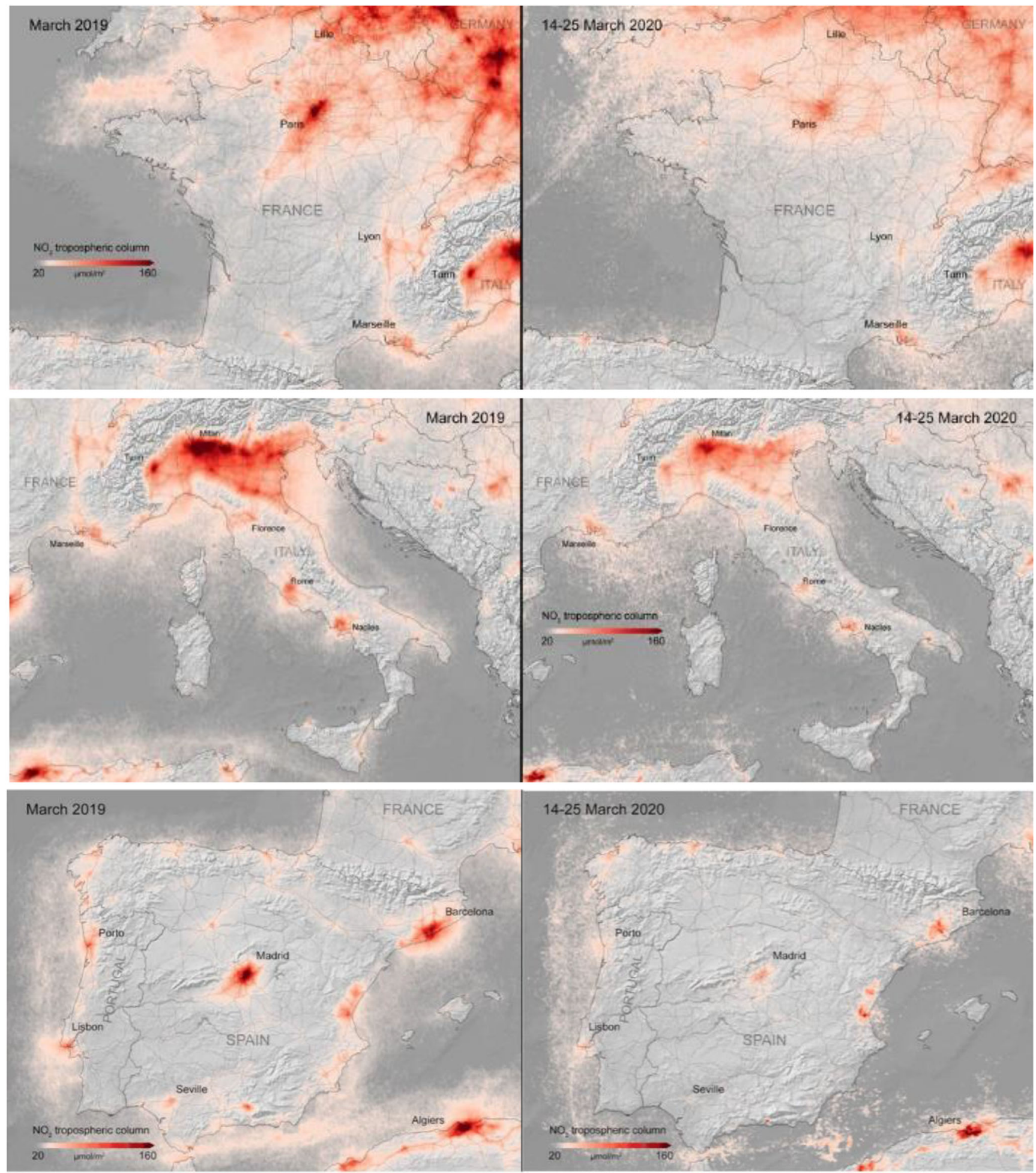

Fig. 5 Variation in the concentration of $\mathrm{NO}_{2}$ in European countries (Italy, Spain, and France) during COVID-19 lockdowns (ESA 2020)

\section{Conclusion}

In this study, the variation of $\mathrm{NO}_{2}$ which was collected from the satellite (Sentinel-5P) was used to indicate the significant reduction in the level of $\mathrm{NO}_{2}$ in Asian and European countries due to COVID-19 lockdowns. The outcomes indicated that the novel coronavirus is considered a blessing in disguise. The current status of air quality may be temporary but there is a very good opportunity for us (scientists/researchers/students/individuals) to learn/understand from the applied 
lockdown activities on how to minimize the concentration level of air pollutants on a long-term basis.

Acknowledgments SG would like to thank the National Aeronautics and Space Administration (NASA) and European Space Agency (ESA), USA. SG is also thankful to Karunya University, Coimbatore, Tamil $\mathrm{Nadu}$, India, for providing us the required funding and support during fieldwork and analysis.

\section{References}

Arden Pope C, Burnett Richard T, Thurston George D, Thun Michael J, Calle Eugenia E et al (2004) Cardiovascular mortality and long-term ex-posure to particulate air pollution. Circulation 109:71-77

Chen H, Guo J, Wang C, Luo F, Yu X, Zhang W, Li J, Zhao D, Xu D, Gong Q, Liao J, Yang H, Hou W, Zhang Y (2020) Clinical characteristics and intrauterine vertical transmission potential of COVID19 infection in nine pregnant women: a retrospective review of medical records. Lancet 20:30360-30363

Cohen AJ, Brauer M et al (2017) Estimates and 25-year trends of the global burden of disease attributable to ambient air pollution: an analysis of data from the Global Burden of Diseases Study 2015. Lancet 17:30505-30506

ESA (2020) ESA, 2020. doi. https://www.esa.int/Applications/ Observing the_Earth/Copernicus/Sentinel-5P

Faustini A, Rapp R, Forastiere F (2014) Nitrogen dioxide and mortality: review and meta-analysis of long-term studies. Eur Resp J. https:// doi.org/10.1183/09031936.00114713

Gautam S (2020) The influence of COVID - 19 on air quality in India: a boon or inutile. Bull Environ Conta Toxicol. https://doi.org/10. 1007/s00128-020-02877-y

Gautam S, Hens L (2020) SARS-CoV-2 pandemic in India: what might we expect? Environ Develop Sustain 22:3867-3869

Gautam S, Trivedi UK (2020) Global implications of bio-aerosol in pandemic. Environ Develop Sustain 22:3861-3865

He MZ, Kinney PL, Li T, Chen C, Sun Q, Ban J, Wang J, Liu S, Goldsmith J, Kioumourtzoglou MA (2020) Short- and intermediate-term exposure to NO2 and mortality: a multi-county analysis in China. Environ Pollut 261:114165
Humbal C, Gautam S et al (2019) Evaluating the colonization and distribution of fungal and bacterial bioaerosol in Rajkot, western India using multi-proxy approach. Air Qual Atmos Health 12(6):693-704

Liu W, Tao ZW, Lei W, Ming-Li Y, Kui L, Ling Z, Shuang W, Yan D, Jing L, Liu HG et al (2020) Analysis of factors associated with disease outcomes in hospitalized patients with 2019 novel coronavirus disease. Chin Med J. https://doi.org/10.1097/CM9. 0000000000000775

Muhammad S, Long X, Salman M (2020) Covid - 19 pandemic and environmental pollution: a blessing in disguise? Sci Tot Environ $728: 138820$

National Aeronautics, Space Administration (2020) NASA:2020 https:// earthobservatory.nasa.gov/images

Ogen Y (2020) Assessing nitrogen dioxide (NO2) levels as a contributing factor to coronavirus (COVID-19) fatality. Sci Tot Environ 726: 138605

Persinger RL, Poynter ME, Ckless K, Janssen-Heininger YMW (2002) Molecularmechanisms of nitrogen dioxide induced epithelial injury in the lung. Mol Cell Biochem 234:71-80

Saeha S, Bai L et al (2020) Association between road traffic noise and incidence of diabetes mellitus and hyperten-sion in Toronto, Canada: a population-based cohort study. J Am Heart Assoc 9: 013021

Sharma S, Zhang M, Anshika GJ, Zhang H, Kota SH (2020) Effect of restricted emissions during COVID-19 on air quality in India. Sci Tot Environ 728:138878. https://doi.org/10.1016/j.scitotenv.2020. 138878

World Health Organization (2020) Coronavirus disease (COVID-2019) situation reports. Geneva: World Health Organization. Retrieved March 23, 2020 from (https ://www.who.int/emerg encie s/disea ses/novel -coron aviru s-2019/situa tion-repor ts/. opens in new tab).

Wu C, Chen X, Cai Y, Xia J, Zhou X, Xu S, Huang H, Zhang L, Zhou X, Du C, et al. (2020) Risk factors associated with acute respiratory distress syndrome and death inpatients with coronavirus disease 2019 pneumonia in Wuhan, China. JAMA Intern.Med. https://doi. org/10.1001/jamainternmed.2020.0994Published online March 13,2020.5Y. Ogen / Sci Tot Environ 726: 138605

Publisher's note Springer Nature remains neutral with regard to jurisdictional claims in published maps and institutional affiliations. 